\title{
QUEVEDO: LABIOS EN VEZ DE PÁRPADOS
}

Soy, desde hace mucho, lector de la poesía de Quevedo, pero no de lo que en nuestros días se escribe acerca de ella. Dejé de estar "al corriente" en 1972. Tal vez por eso me ha llamado tanto la atención el libro de Santiago Fernández Mosquera sobre la poesía amorosa, enviado a la NRFH para reseña ${ }^{1}$. No se parece nada a los estudios "filológicos" o "estilísticos" que conozco (Leo Spitzer, los dos Alonsos, Raimundo Lida, Carlos Blanco Aguinaga...). Tampoco se parece, por fortuna, a las especulaciones desconstruccionistas que ahora se usan, tan vanas como difíciles de leer. Mosquera tiene los pies firmemente asentados en el terreno de la antigua Retórica. La parte sustancial de su libro son las 235 páginas del capítulo 2, "El estilo de Canta sola a Lisi", donde estilo no tiene que ver con "estilística", sino con retórica?2. Estas 235 páginas van precedidas de 40 (cap. 1) sobre el sello de canzoniere petrarquesco que puso Quevedo en sus poemas a Lisi, y seguidas de otras 40 (cap. 3) sobre "El yo poético [y también el tú y el vos] de Canta sola a Lisi". (Hay finalmente un bien documentado y muy útil "Apéndice textual".)

El cap. 2, el sustancial, consta de tres secciones: 1) "Los tropos y los tópicos"; 2) las "Figuras de dicción", y 3) las "Figuras de pensamiento". El primero de los tropos es la metáfora (que se lleva, naturalmente, la parte del león: pp. 57-165). Vienen ante todo las metáforas para 'pasión amorosa' (cárcel, cadenas, redes...), en seguida las que toman elementos de la naturaleza: animales (víbora, salamandra, abeja, mariposa, águila, ruiseñor, "fieras y leones"), vegetales (clavel, rosa, jazmín, hiedra, vid, laurel...) y minerales (oro, rubíes, mármol...); si-

${ }^{1}$ La poesía amorosa de Quevedo. Disposición y estilo desde "Canta sola a Lisi", Gredos, Madrid, 1998, 419 pp. (Abreviaré: MosQuera.)

2 Declara Mosquera que su estudio es el primero que aplica "un modelo tradicional retórico -Quintiliano, por ejemplo- al estilo de la poesía amorosa de Quevedo"; pero reconoce como precursores a J. M. Pozuelo, El lenguaje poético de la lírica amorosa de Q. (1977), P. J. Smith, Q. on Parnassus (1987) y M. Roig Miranda, Les Sonnets de $Q$. (1989), estudios que no conozco. 
guen las metáforas basadas en "elementos físicos y meteorológicos" (fuego, agua y sus respectivas "isotopías"), las "metáforas astronómicas y cosmológicas" (esfera, sol, estrellas...) y las "mitológicas" (Ícaro, Tántalo, Leandro, las Furias, el Fénix...). Tras esto viene el largo desfile de las "figuras de dicción": por repetición (reduplicatio o anadiplosis, gradatio, geminatio, redditio, annominatio, complexio...), por acumulación (enumeratio, distributio, epitheton...), por supresión (zeugma) y por ordenación (hipérbaton, isocolon), y finalmente el desfile también largo de las "figuras de pensamiento" (apostrophe, interrogatio, subiectio, antitheton, oxymoron, commutatio o retruécano, paradoja, exclamatio, sermocinatio, prosopopeya...).

Esta lista es selectiva. No da una idea justa del libro, cuyo rasgo más saliente es la exhaustividad, la atención a los detalles finos, las ramificaciones, las distinciones, las correlaciones, los matices. En la "familia" del antitheton, por ejemplo, están la finitio, la conciliatio y la correctio (p. 249), y en la de la annominatio están la annominatio mix$t a$, la paronomasia, el polyptoton, la derivatio, la figura etymologica y un macho e fembra que no sé qué será (p. 186). Las fronteras entre una y otra figura suelen difuminarse, y a menudo se dan saltos de una a otra. En los vv. 31-36 del idilio que comienza "¿Aguardas por ventura...?" observa Mosquera (p. 245) "un claro diálogo fingido que nace en una subiectio para convertirse en una clara sermocinatio"; y de la imagen 'los ojos hablan' (soneto “¿Cómo es tan largo en mí dolor tan fuerte...?", v. 14) dice que "puede ser considerada una prosopopeya, una metáfora sinestésica o una hipálage, que también se relaciona con la imagen sintáctica" (p. 275) ${ }^{3}$.

Yo me confieso medianamente capaz de seguir el hilo o los hilos de este libro; no me escandalizan los tecnicismos grecolatinos; sé lo que es geminatio y lo que es oxymoron. Pero me pregunto si habrá muchos lectores como yo. Conozco a amantes de la poesía de Quevedo para quienes lo que ha hecho Mosquera resultará insufriblemente académico. $\mathrm{Su}$ reacción será como la mía frente a los libros y artículos que llamo neoacadémicos, con sus actantes, sus redes actanciales, sus actores sintácticos homodiegéticos y heteroextradiegéticos y tantos otros exquisitos terminachos ${ }^{4}$. Esos quevedófilos - algunos de los cuales se saben de memoria más de un soneto- encontrarán tan "tapido de jerigonzas" el discurso de Mosquera como el de los neo-académicos, y no verán ningún provecho en la reaparición de Quintiliano.

${ }^{3}$ Mosquera se sirve mucho, como es natural, del Manual de retórica literaria de Heinrich Lausberg (lo ha tenido literalmente en la mano). Pero, por lo visto, ni aun esta minuciosísima guía ha bastado para dejar bien preciso el campo de acción de ciertos tropos o figuras.

${ }^{4}$ Cf. "Crítica literaria tradicional y crítica neo-académica", en mis Ensayos sobre crítica literaria, México, 1993, pp. 55-77; también "Lingüística y literatura", ibid., pp. 89-108. 
La empresa de Mosquera tiene, pues, algo de heroico. Hay que pensar en el tiempo que le ha llevado leer los poemas de Canta sola a Lisi pasaje por pasaje, verso por verso, descubrir las apariciones y hasta las insinuaciones de cada tropo y cada figura, registrarlas todas en "papeletas" y clasificarlas y ordenarlas (a lo cual hay que añadir la minuciosa utilización de una bibliografía considerable). Parece que nos hallamos ante una reacción contra las divagaciones "postmodernas", una especie de reivindicación de la antigua Retórica, una muestra de la supervivencia de la tradición clásica y humanística ${ }^{5}$.

Falta añadir que Mosquera, para situar mejor los medios expresivos de Canta sola a Lisi, somete a idéntico análisis no sólo el resto de los poemas eróticos de Quevedo, sino también la poesía amorosa de Fernando de Herrera y la de Francisco de la Torre, que tienen algo de canzoniere, así como las Rimas de Tomé de Burguillos, que son un canzoniere paródico (y una de las manifestaciones más graciosas de ese fenómeno europeo que fue el antipetrarquismo). Herrera, Torre y Lope de Vega - "tres estadios, tres momentos y tres ambientes distintos" (p. 12) - son objeto del mismo escrupuloso rebusco de tropos y figuras. Hay entre los cuatro, como es natural, algunas diferencias, pero sobre todo muchas coincidencias: los cuatro acuden a rosas y lirios, los cuatro emplean la anadiplosis y la interrogatio, etc.

El resultado a que llega Mosquera en las "Conclusiones generales" es un tanto desconsolador. Tiene toda la razón al recalcar la "profunda novedad" de la poesía amorosa de Quevedo "con respecto a los poetas cercanos a él en el tiempo"; pero reconoce que sus laboriosos análisis no han servido para mostrar en qué consiste esa novedad, esa individualidad: "En el estudio de los tropos y tópicos utilizados por Quevedo... destacamos las escasas novedades que aporta dentro de la poesía áurea. De hecho, tópicos y metáforas son las habituales en los poetas de su momento y nacen, fundamentalmente, de la tradición clásica matizada por el petrarquismo italianizante del xvi español" (p. 281) ${ }^{6}$. Lo cual significa (según yo) que la mane-

${ }^{5}$ Los nombres de todas las "figuras" están limpios de erratas en este libro. Pero, si se trata de preservar la tradición humanística, sería bueno atender de una vez a los detalles pequeños. Mosquera escribe oximoron y políptoton, palabras que debieran ser llanas, pues la $o$ central procede de omega. A veces cuesta trabajo integrar estos tecnicismos en un discurso corrido. Mosquera, que usa plurales grecolatinos ("los isocola" y "los tricola", p. 224), dice también (p. 256) "los oxímoros" (tal como Dámaso Alonso dijo "los hipérbatos"), pero en plurales como "las derivatio" (p. 188), "las interrogatio", "las subiectio" y "las correctio" (pp. 243 y 250) es muy violento el choque de lo "humanístico" de la palabra con lo bárbaro de la construcción.

${ }^{6}$ Para unas pocas figuras de dicción, como el epitheton, el hipérbaton y el isocolon, Mosquera toma también en cuenta a Góngora, y a propósito del isocolon (bimembración y plurimembración) dice que su "abrumadora presencia" en Quevedo lo acerca a Góngora y lo aleja de Herrera, Torre y Lope (p. 284). 
ra de estudiar la "profunda novedad" de Quevedo no es la que Mosquera ha elegido.

A mí, lector de Quevedo, siempre me ha llamado la atención la profunda novedad de un grupo de sonetos que comienzan con una proposición condicional y que en seguida, una vez asentada la condición, despliegan las consecuencias que de ello se desprenden. Son típica, descaradamente quevedescos. Los llamaré "sonetos de hipótesis". Aunque la hypothesis pertenece de lleno al campo de la retórica, Mosquera no presta atención a esos sonetos. He aquí un clarísimo ejemplo:

Si mis párpados, Lisi, labios fueran, besos fueran los rayos visüales de mis ojos, que al sol miran, caudales águilas, y besaran más que vieran.

Tus bellezas, hidrópicos, bebieran, $\mathrm{y}-$ cristales sedientos de cristalesde luces y de incendios celestiales alimentando su morir, vivieran.

De invisible comercio mantenidos y desnudos de cuerpo los favores, gozaran mis potencias y sentidos; mudos se requebraran los ardores; pudieran, apartados, verse unidos, y en público secretos los amores.

Este soneto ha dado materia para no pocas anotaciones de Mosquera. El primer cuarteto ejemplifica la metáfora águila (p. 81); el vocativo "Lisi" del v. 1 es ejemplo de apóstrofe (p. 236); los vv. 1-2 pueden ser ejemplo de geminatio, o bien de reduplicatio o anadiplosis, pues "la frontera entre ambas [figuras] no está clara" (p. 181); en los vv. 2-3 hay "presencia del motivo ojos" (p. 45); en los vv. 3-4 hay la metáfora sol 'ojos' (p. 130); los vv. 4-5 y 8, con sus besaran, vieran, bellezas, bebieran y vivieran, muestran una paronomasia "que, desde otra perspectiva, también puede denominarse aliteración” (p. 186); los vv. 5-6 ejemplifican la metáfora cristal 'agua' $\longrightarrow$ 'lágrimas' (p. 108); el v. 6 es un caso de redditio, "figura intensiva y encarecedora” (p. 182), y también de prosopopeya, "que supone aplicar una cualidad humana a un objeto" (p. 275); los vv. 6-7 ejemplifican la metáfora luz 'ojos' y los vv. 7-8 la metáfora incendio, también 'ojos' (pp. 116 y 117); finalmente, el v. 14 es un caso de oxymoron (p. 256).

Estos disiecta membra, que pertenecen solamente a los cuartetos, se parecen más o menos a otros disiecta membra de Herrera, Torre y Lope, pero no dan la más mínima idea de lo que es el soneto de Que- 
vedo. Los tercetos no han suministrado alimento para ninguna papeleta, fuera del oximoron del verso final, amores al mismo tiempo "secretos" y "en público". (De hecho, el oximoron es más amplio: vida que da alimento a la muerte, ardores que se requiebran aunque mudos, y que se unen, aunque apartados.) Los cuartetos suponen, desde luego, una "tradición clásica matizada por el petrarquismo", pero a la red tan cuidadosamente tendida por Mosquera se le escapa algo que no está en Herrera ni en Torre ni en Lope: la peregrina y loca fantasía de unos párpados convertidos en labios (¿catacresis se llama esta figura?). El inexorable código del amour courtois prohíbe aun la menor insinuación de contacto físico entre la dama y el amante; lo único lícito son las miradas (por lo general no correspondidas); pero si el amante tiene labios en vez de párpados, podrá hacer todo lo que el código veda: los antes ojos y ahora labios besarán impunemente a Lisi y beberán a grandes tragos sus bellezas ${ }^{7}$. En los tercetos, clímax del soneto, da Quevedo un salto más atrevido. Un amante tan milagrosamente favorecido por los dioses no va a contentarse con ver y besar a la dama: con la misma impunidad dará el último paso. La expresión "en público" sugiere un evento social (una función de teatro, una misa, una fiesta palaciega) que da al amante la oportunidad de mirar largamente a la dama; sólo que ahora no la está mirando, pues no tiene ojos, sino labios. En vez de una mirada sostenida, lo que hay es un coitus ininterruptus. Es lo que dicen los tercetos. Tal es la pointe del soneto.

La infracción del código del amour courtois, aun por hipótesis, significa naturalmente una ruptura con las convenciones del petrarquismo. El "presupuesto" de los versos de Petrarca, de Herrera y de Torre es el deseo de unión carnal, pero éste va siempre delicadamente escondido entre líneas; Quevedo lo saca de su escondite; su "profunda novedad" consiste en ir siempre más allá; a la retórica petrarquesca le sobreañade su retórica personal, tan outrée, tan desaforada.

El subterfugio de la hipótesis ("Si mis párpados...") se parece al subterfugio del sueño en "Ay, Floralba, soñé que te... ¿dirélo?...”: ¡qué consuelo celestial, para el suspirante y nunca correspondido amante, soñar que tiene en los brazos a la dama, o siquiera que, por fin, ve en su rostro un destello de ternura o compasión! En tiempos de Quevedo existía ya toda una tradición de "sonetos de sueño erótico" (a partir del hermoso "Dulce soñar y dulce congojarme..." de Boscán), con su código, sus convenciones, en una palabra, su retóri-

7 En el verso "y cristales sedientos de cristales", los segundos cristales son, desde luego, los níveos miembros de Lisi, pero los primeros son problemáticos: si se tratara de 'ojos' no habría mucho problema; pero de lo que se trata es de unos 'labios' ansiosos por beber. En todo caso, no veo las 'lágrimas' que Mosquera cree descubrir. 
$\mathrm{ca}^{8}$. Lo que sigue al "Soñé que..." varía de un soneto a otro, pero se observan siempre las reglas del decoro. Por eso es tan sensacional el comienzo de "Ay, Floralba...”: en los dos primeros versos, despojándose de toda cobertura petrarquesca, Quevedo va al grano y llama pan al pan: "Soñé que te gozaba" (y, para mejor acentuar lo fuerte de la expresión, mete con mucho tino el “¿Dirélo?”). Es una de las maneras que tiene de ir "más allá": ningún soneto de sueño erótico había comenzado como el suyo.

(El caso de Francisco de Aldana es muy especial. Sus poesías de amor están hechas en Italia, y los poetas italianos de sus tiempos, por mucho que siguieran venerando a Petrarca, ya no petrarquizaban: tenían los pies en el suelo y cantaban con toda naturalidad la joie de vivre. En Aldana no hay melancolía, sino celebración del amor consumado. Él no necesita hacer la hipótesis 'si tuviera labios en vez de párpados', sino que comienza el soneto “¿Cuál es la causa, mi Damón...?” con la descripción extraordinaria - en todos sentidosde un coito realy maravilloso 9 . Otro soneto de Aldana, "Galanio, tú sabrás que esotro día...", rompe muy de propósito con la retórica de los sonetos de sueño erótico: los cuartetos ponderan el "abrazo enamorado", pero los tercetos no comienzan, como era de rigor, con un ‘Ay de mí!, desperté y vi que era sólo un sueño’, sino con un gozoso "No desperté".) 10

Otro notable ejemplo de "soneto de hipótesis" es el que comienza "Si hija de mi amor mi muerte fuese...". Aquí el punto de partida es mucho más estrambótico que en "Si mis párpados...": podemos representarnos una figura que tenga labios en vez de párpados, pero ¿cómo representarnos a la Muerte como hija del Amor, al Amor pariendo a la Muerte? En "Si mis párpados..." hay tres consecuencias de la hipótesis, minuciosamente razonadas. En el otro, tras el impresionante verso inicial, lo que hay es una simple expansión o inflación del tema 'Amor constante más allá de la Muerte', como reza el epígrafe del celebérrimo "Cerrar podrá mis ojos la postrera/ sombra...”.

Estamos muy a oscuras en cuanto a la cronología de los versos de Quevedo (iqué enorme contraste con los de Góngora!), pero tengo

${ }^{8}$ En el Viage del parnaso, VI, 34, dedica Cervantes una rápida sonrisa a estos sonetos acumulados a lo largo de un siglo: "Gocé durmiendo cuatro mil despojos/ (que los conté sin que faltase alguno)/ de gustos que acudieron a manojos”.

${ }^{9}$ Este soneto va de lo carnal a lo neoplatónicamente espiritual, mientras que "Si mis párpados..." tiene un recorrido inverso: de lo inmaterial (mirada) a lo físico. Vale la pena observar que el soneto “¿Cuál es la causa, mi Damón...?” fue parafraseado por Quevedo en el madrigal "Los brazos de Damón y Galatea...”.

${ }^{10}$ Hay, por supuesto, muchos otros sonetos directamente eróticos, como los editados por P. Alzieu et al. en su reveladora Poesía erótica del Siglo de Oro (1975), sonetos a veces muy buenos, pero que no corrían sino en copias manuscritas. Y Alzieu y sus colegas omiten muchos por no tener más chiste que el porrazo de la obscenidad. 
la impresión de que el punto de arranque de los "sonetos de hipótesis" es uno de Luigi Groto, "Se 'l diluvio di Giove in terra steso...". Quevedo, como todos sus contemporáneos, imitó a los poetas italianos, pero ninguna de sus imitaciones ${ }^{11}$ es comparable con ésta. Puede ponerse dignamente al lado de las maravillosas que había hecho el joven Góngora, con la diferencia de que la traducción de Quevedo es menos libre, más ceñida al original. El soneto de Groto es "barroquización" de otro de Serafino Aquilano12, en el cual están ya las cuatro "hipótesis" que sirven de estructura a los de Groto y Quevedo: 'Si se acabara todo el fuego, yo lo repondría con las llamas de mi pecho; si el agua, con el llanto de mis ojos; si ya no hubiera vientos, los restituirían mis suspiros; si se agotaran los tormentos del infierno, ocuparían su lugar los míos'. El soneto de Quevedo es "super-barroquización" del de Groto. El concepto de "imitación creadora" viene aquí muy al caso ${ }^{13}$. Ese tono personal de Quevedo, esa desmesura, está ya en el primer verso, que convierte el "diluvio" de Groto en cantidad de diluvios vomitados por el abismo.

De los recursos retóricos tradicionales, el más constantemente utilizado por Quevedo para lucir su "agudeza" y su "arte de ingenio" es la hipérbole. A primera vista, parece escandaloso que Mosquera no dedique sino tres páginas y media (172-175) a este "tropo"; pero es que aquí los ejemplos no tendrían fin; la hipérbole, como él dice muy bien, es el "ambiente general" de toda la poesía amorosa de Quevedo. ¿Y qué mejor tierra de cultivo para la hipérbole que la hypothesis? Lo jugoso de "Si mis párpados..." y de "Si hija de mi amor..." está en las estupendas hipérboles que vienen a continuación. Ingenio a toda costa: tal es la "marca de fábrica" de Quevedo"

La hipérbole es el "ambiente general" no ya de Canta sola a Lisi, ni del resto de los versos amorosos de Quevedo, sino de toda su poesía. (Y aun de su prosa: sin hipérbole no habría Buscón ni España defendida ni muchas otras cosas.) Hay "sonetos de hipótesis" en las tres

11 Pueden verse en Joseph G. Fucilla, Estudios sobre el petrarquismo en España, Madrid, 1960, pp. 195-209.

${ }^{12}$ Sobre las traducciones españolas del soneto de Serafino ("Se 'l gran tormento i fier fulmini accesi...") véase Fucilla, op. cit., pp. 231, 244 y 278.

13 ¿Qué gracia puede tener - entonces y ahora- una imitación que no añada algo a lo imitado? Lo dice muy bien Herrera (Anotaciones, p. [190]) a propósito de un soneto compuesto por Gutierre de Cetina a imitación de Garcilaso: "No sé si [lo hizo] tan bien que mereciesse alabança por ello; quien lo leyere con atención verá claramente el efeto que consiguió [o sea: ningún efecto]; porque yo no tengo por ingenio obligarse a cosas semejantes, que... después de trabajadas no alcançan en alguna parte a la imagen que escogieron por exemplo".

14 Aun a costa del plagio. El bonito concetto final del ya mencionado "Ay Floralba..." ("Quiera mi suerte/ que nunca duerma yo si estoy despierto,/ y que si duermo, que jamás despierte”) está tomado de un soneto del P. Tablares, "iAy, dulce sueño y dulce sentimiento...!". Como Tablares era un oscuro poeta del siglo xvi a quien ya nadie leía, Quevedo pudo apropiárselo con toda tranquilidad. 
principales "modalidades" de su poesía: la seria (metafísica, moral, religiosa), la amorosa y la burlesca (chistosa, satírica). De los 45 sonetos que comienzan con la conjunción $S i^{15}$, la mayoría -20 sonetosson filosófico-morales (incluyendo los "epitafios" y el soneto en portugués "Se casto ao bom Joseph nomea a fama..."); los burlescos son 12 , y los amorosos son 13. Valdría la pena que alguien - ¿y por qué no el propio Mosquera? - analizara exhaustivamente estos 45 sonetos $^{16}$ y los comparara desde el punto de vista estructural unos con otros (y con los sonetos de $S i$ inicial de Herrera, Torre y Lope), y hasta ensayara una "tipología" de ellos. Por principio de cuentas habría que ver el matiz de la conjunción $\mathrm{Si}$, que suele no ser condicional, de manera que varios de los 45 sonetos no serían propiamente "de hipótesis"17. Muy pronto se formarían dos grupos estructuralmente distintos, de acuerdo con la índole de las hipótesis: unas son imposibles, por ejemplo "Si mis párpados, Lisi, labios fueran...", y otras posibles, por ejemplo "Si fuere que después al postrer día...". Por mi parte, tomaré de entre las tres "modalidades" un manojito de "sonetos de hipótesis" para hacerles unas cuantas apostillas.

Comienzo con "Si fuere que después al postrer día...". Aquí lo que menos importa es la hipótesis. La duda que se expresa, "Si después de mi muerte alguien lee mis poemas amorosos...', no es verdadera duda, sino falsa modestia, coquetería. Lo que importa es el cuerpo del soneto (variante de "Cerrar podrá mis ojos..."). Pero el Si inicial tiene la función de crear en el lector una "expectativa”.

Es lo que ocurre en "Si me hubieran los miedos sucedido/ como me sucedieron los deseos...". Lo que sigue a tan "metafísica" hipótesis es un simple despliegue de preceptiva estoica: acumular riquezas es perder "la paz y el ocio" para lograr "pena y gemido". Es lo que ocurre también en el divertido "Si alumbro yo por que a matar aprendas...": en el cuarteto inicial habla el candil a cuya luz repasa sus aforismos un estudiante de medicina (un aprendiz de asesino), pero en el resto habla más bien el propio Quevedo, soltando sus habituales chistes sobre el funesto gremio de los matasanos (por ejemplo: para el aprendiz de médico hasta el comer es lección útil, pues comiendo mata al hambre). En “Si dádivas quebrantan duras peñas...”, la pró-

15 Unas pocas poesías con $S i$ inicial no son sonetos, como el madrigal "Si fueras tú mi Eurídice, señora..." (imitación agigantada del de Luigi Groto, "Se 'l dotto Orfeo die gran segno d'amore...") y las liras "Si el tiempo que gasté contigo lloro...", donde la misoginia de Quevedo necesitó 84 versos para explayarse.

16 Salvo una ligera mención de "Si de un delito proprio..." y de "Si Venus hizo de oro...", Mosquera no toma dato alguno de los 32 sonetos que no son amorosos.

17 Por ejemplo, en "Si a Dios me debo todo, porque he sido/ a semejanza suya fabricado...", el Si significa 'puesto que', 'siendo así que'; lo mismo en "Si vivas estas carnes y estas pieles..." (las chinches y los piojos son una dura realidad), o en "Si de cosas diversas la memoria/ se acuerda...", etc. 
tasis va seguida inmediatamente de su apódosis, y el resto del soneto se dedica a encadenar reflexiones sobre las bondades de Cristo.

En "Si mis párpados...”, la hipótesis vale para los cuartetos, pero ya no para los tercetos. Y justamente por eso siento que es éste el más representativo de los "sonetos de hipótesis": muestra la importancia que da Quevedo a los inicios novedosos, su afán de asombrar y de lucirse lo antes posible. Aturdido por los espectaculares cuartetos, el lector no va a darse cuenta de que los tercetos son "ilógicos", puesto que en el coito no tienen nada que hacer los párpados. No es un soneto "unitario".

Hay sonetos que se parecen a "Si mis párpados..." por la índole de la hipótesis, pero que son más "unitarios", más congruentes. En "Si de un delito proprio es precio en Lido..." y en "Si a los que me merecen me entregara...", el Si del comienzo sigue presente hasta el final ${ }^{18}$. A veces, para marcar la continuidad de la hipótesis, se repite a lo largo del soneto el Si inicial, como en "Si vistes a las piedras quebrantarse...,/ si supieron las piedras animarse..." -que es una especie de correlato de "Si dádivas quebrantan duras peñas..."-, o en "Si tu país y patria son los cielos...,/ si tu deidad blasona por abuelos...", o en "Si vieras que con yeso blanqueaban...,/ si vieras que al clavel...", etc., -soneto que desarrolla bien una sola idea: es desatino que las mujeres bonitas se sirvan de afeites ('Si las flores necesitaran maquillaje, entonces estaría bien'). Lo mismo vale para el desaforado "Si el cuerpo reluciente que en Oeta...", donde las cuatro hipótesis de "Si el abismo en diluvios desatado..." se concentran en una sola, con eficaz trabazón de prótasis y apódosis.

Vale la pena releer "Si las mentiras de fortuna...", soneto profundamente "moral" en que el poeta se dirige al orgulloso Licas para decirle que los bienes de fortuna son efímeros (la muerte va a dar un contundente mentís a sus presunciones). Y, una vez releído, vale la pena compararlo con "Si no duerme su cara con Filena...", soneto desenfrenadamente "burlesco" en que el poeta acumula chistes sobre una dama constituida sólo por afeites, postizos y perendengues ${ }^{19}$, de manera que sin ellos queda hecha nada, tal como el presuntuoso Licas queda hecho nada al morir. Tan "moral" es un soneto como el otro: los moralistas condenan la ostentación de los magnates lo mismo que los afeites mujeriles. Son sonetos hermanos, así por la estructura como por el "mensaje".

18 Lo que dicen estos dos sonetos es lo mismo que, con gran economía, había dicho Góngora en la muy juvenil letrilla "Da bienes Fortuna...": "Porque en una aldea/ un pobre mancebo/ hurtó solo un huevo,/ al sol bambolea; / y otro se pasea/ con cien mil delitos./ Cuando pitos, flautas;/ cuando flautas, pitos".

${ }^{19}$ Muy parecida a la "casada y rica" de La hora de todos, xII, que "cubría con hopalandas de solimán unas arrugas jaspeadas de pecas, jalbegaba como puerta de alojería lo rancio de la tez, estábase guisando las cejas con humo, como chorizos...”, etc. 
La "estructura" de "Si no duerme su cara con Filena..." es, simplemente, la sarta de agudezas e hipérboles. (Se parece mucho a la de "Antes del repelón eso fue antaño...", ristra de imágenes que ponderan "los años de una vieja niña".) El soneto "Si un Eneíllas viera, si un pimpollo..." es como estampa o episodio de un Virgile travesti: la cadena de reproches de Dido se convierte en una cadena de chistes y calembours. Otro buen ejemplo es "Si en no salir jamás de un agujero...", que, tras deplorar que las doncellas no imiten a la araña en quedarse en casa y estarse hilando, pasa a enumerar las cosas nefastas en que sí la imitan. El soneto "Si caístes, don Blas, los serafines/ cayeron de las altas jerarquías...", sobre un "toreador que cae siempre de su caballo y nunca saca la espada", es un brillante desfile de retruécanos a base del verbo caer $^{20}$. La obra maestra de este grupo es el soneto "Si la ballena vomitó a Jonás...", que contiene como en una mínima cápsula la historia del profeta -con la orden de ir a Nínive, y la tempestad, y la ballena-, y simultáneamente cuenta los avatares del mamarracho de pintura en que Eugenio Cajés quiso representar la famosa historia.

Pongo como remate dos sonetos de la misma índole que los anteriores - sarta de ingeniosidades, juegos de palabras y de conceptos en competencia unos con otros-, pero que parecen formar un grupo retórico aparte. Los dos repiten, anafóricamente, la conjunción Si. El primero, "Si dios eres, Amor, ¿cuál es tu cielo...?”, es una guirlanda de preguntas retóricas en vituperio de Cupido. El segundo, "Si eres campana, ¿dónde está el badajo...?”, sería una lluvia de adivinanzas difíciles de resolver si no fuera porque el epígrafe, piadosamente, nos da la clave: "Mujer puntiaguda con enaguas". En el primer soneto el poeta se dirige insolentemente al falso dios Cupido, pero en el otro no se dirige a la mujer de moño piramidal y enormísimas enaguas, sino a las cosas heterogéneas que algo, o alguien, parece ser: podría ser una campana, pero carece de badajo; o una pirámide, pero no está en Egipto; o una peonza al revés..., etc.; apenas en el verso final se le ocurre al poeta que eso pueda ser una mujer ("si mujer, ¡da esas faldas al demonio!") 21.

Por su desbordamiento de humor, este soneto se parece no poco al muy celebrado "Érase un hombre a una nariz pegado...", también anafórico, también retahíla de comparaciones a cuál más chusca,

${ }^{20}$ Retruécanos que le gustan a Quevedo. Cf. una carta suya de 1624 al marqués de Velada: "Yo caí; San Pablo cayó; mayor fue la caída de Luzbel..." (Prosa, ed. Astrana, 1941, p. 1714); y otra al mismo: "Vuestra merced cayó; San Pablo cayó y Luzbel cayó; y de los tres sólo uno cayó en la cuenta" (ibid., p. 1719).

${ }^{21}$ Esta mujer se parece a la "buscona piramidal" de La hora de todos, x, que "salía de su casa habiendo hecho sudar la gota tan gorda a su portada dando paso [al dar paso] a un inmenso contorno de faldas... Cogióla la hora, y volviéndose del revés las faldas del guardainfante, y arboladas, la sorbieron en campana vuelta del revés, con facciones de tolva”. 
pero es mejor aún, más chispeante, a lo cual contribuyen unas rimas que parecen mandadas hacer para la caricatura (y que faltan en "Érase un hombre..."): badajo, encajo, arrendajo, viejas, guedejas...22.

La adscripción a una u otra de las "modalidades" poéticas de Quevedo -la amorosa, la seria (filosófica, religiosa, etc.) y la burlesca o satírica- suele ser floja o caprichosa. Buen ejemplo de ello es el soneto "Si a una parte miraran solamente...", donde el poeta se dirige "a una dama bizca y hermosa" para decirle: 'Si tus ojos estuvieran bien enfocados, una mirada tuya sería letal; por eso un dios compasivo hizo que el derecho mirara a una parte y el izquierdo a otra' ( $\mathrm{y}$ al final deplora que los ojos, siendo "monarcas", se vean degradados a "vizcondes"). Para mí, y creo que para todo buen lector, éste es un soneto burlesco hecho y derecho, pero tanto Astrana Marín como Blecua lo consideran "amoroso", seguramente porque está en la Musa Erato, que "canta hazañas del amor i de la hermosura" (como si González de Salas fuera la última palabra). Hay varios casos parecidos. Los sonetos "Si a los que me merecen me entregara..." y "Si de un delito proprio es precio en Lido..." son paralelos: no tiene mucho sentido poner el primero entre los "morales" y el otro entre los "burlescos" 23 . El soneto "Si de cosas diversas la memoria..." dice: 'Puesto que en la memoria, el entendimiento y la voluntad (las tres "potencias del alma") caben infinidad de cosas, también en mi pecho puede haber lugar para más de una dama'. ¿Qué diría Lisi al recibir semejante "poema amoroso"? ¿Y qué hubiera dicho Petrarca? Estamos muy lejos de "Hoy cumple Amor en mis ardientes venas..." y de "A fugitivas sombras doy abrazos...". Tampoco es poema "amoroso", sino vituperio del Amor, el soneto "Si tu país y patria son los cielos...", donde el poeta pregunta: "Ser dios y enfermedad, ¿cómo es posible?”; y aún menos "amoroso" es el ya citado "Si dios eres, Amor, ¿cuál es tu cielo...?”, donde el poeta increpa a Cupido: 'Dices ser un señor colmado de riquezas, un ser sublime, un dios. ¡Demuéstramelo! Por lo que voy viendo, eres una miserable gallina ciega' ${ }^{24}$.

${ }^{22}$ Quevedo sabe muy bien qué es lo que la gente espera de él, y se esmera en darle gusto: 'He aquí lo que parece la enorme nariz de fulano'; 'He aquí lo que parece esa mujer con su guardainfante y su tocado puntiagudo'; y también 'He aquí lo que parece Ruiz de Alarcón con su par de jorobas’ (letrilla “¿Quién es poeta juanetes...?"). En 1623 diecisiete ingenios de la corte, en una especie de certamen, compusieron sendas décimas para "definir" burlescamente a Alarcón; pero "más feroz que todas las décimas juntas” - como dice WILlard F. KING, Juan Ruiz de Alarcón, letrado y dramaturgo, El Colegio de México, 1989, p. 185- fue la letrilla de Quevedo, cuyas 21 coplas de a seis versos son un continuo fluir de "definiciones": Alarcón es esto, y esto, y estotro.

${ }^{23} \mathrm{Cf}$. la hermandad que he señalado antes entre "Si las mentiras de fortuna, Licas..." " "Si no duerme su cara con Filena...", dos sonetos de sátira social.

${ }^{24}$ Es también el caso de "Llegó a los pies de Cristo Madalena...", con sus cuartetos y su primer terceto tan reverentes y piadosos en apariencia, en realidad mera preparación para el chiste final sobre los "ungüentos" (asquerosos) que venden los 
Gracias a los respectivos índices de primeros versos puede verse cómodamente la presencia de "sonetos de hipótesis" en Fernando de Herrera, Francisco de la Torre y Lope de Vega, que son los puntos de comparación elegidos por Mosquera para La poesía amorosa de Quevedo. Son muy raros en Herrera ("Si puede celebrar mi rudo canto...") y en Torre ("Si lo que el alma me revela, cuando..."); Lope, en cambio, los prodiga bastante, y no sólo en las Rimas de Tomé de Burguillos, sino en todos los libros de versos que publicó ${ }^{25}$. Y existen entre Lope y Quevedo ciertas interesantes analogías. Varios de los sonetos de las Rimas y de las Rimas sacras anuncian a Quevedo, quien admiraba a Lope porque escribía en castellano y no en "jerigonza" culta; no es de sorprender que lo haya imitado ${ }^{26}$. En las Rimas de Burguillos, de 1634, la relación es inversa. Es evidente que Lope conocía las poesías burlescas de Quevedo, aunque sea difícil precisar qué huella le dejaron. Los de "Burguillos" son, desde luego, sonetos para jugar y reír, como los de Quevedo, pero Lope no llega a los extremos a que llegó don Francisco (entre otras cosas, porque tiene la "desventaja" de no ser tan descaradamente misógino); su humor es más sutil, más urbano.

La poesía amorosa es, sin duda, la "modalidad" de Quevedo que más atención recibe en nuestros días. Hay en ella -y sobre todo en Canta sola a Lisi- pensamientos tan peregrinos, imágenes tan alambicadas, sonetos tan bien redondeados, acentos tan cien por ciento quevedescos, que el lector queda embelesado ante tamaño "desgarrón afectivo". A la desoladora conclusión de Mosquera -que dentro de la "poesía áurea” Quevedo "aporta escasas novedades"- opongo esta otra:

Hay un grupo de sonetos -los "sonetos de hipótesis"-que ponen muy de manifiesto una de las muchas formas que tiene Quevedo de "aportar" novedades, una de sus muy personales maneras de no parecerse a nadie (ex ungue leonem). Quevedo posee una retórica muy suya, y tan desbocada (calificativo que cada lector puede sustituir por otro: exquisita, recargada, super-barroca, arrebatadora, demencial, etc.), que inunda todo cuanto escribe, sea de la "modalidad" que sea. Por

boticarios. (Cf. La hora de todos, III: "Atravesaban por otra calle unos chirriones de basura, y llegando enfrente de una botica los cogió la hora, y empezó a rebosar la basura y salirse de los chirriones y entrarse en la botica, de donde saltaban los botes y redomas, zampándose en los chirriones con un ruido y admiración increíble”.) Blecua pone ese soneto entre los "poemas religiosos"; Astrana, aquí más atinado, entre las "sátiras varias".

${ }^{25}$ En Garcilaso hay sólo dos: "Si para refrenar este deseo..." y "Si quejas y lamentos pueden tanto..."; en Góngora hay cuatro, todos ellos serios, más uno "atribuido" que suena mucho a Quevedo: "Si por virtud, Josefa, no mancharas...".

${ }^{26}$ Un mediano conocedor que lea sin nombre de autor el soneto "Si culpa el concebir; nacer, tormento...”, muy probablemente se lo atribuirá a Quevedo, pero es de Lope (Rimas, 1602). 
eso, colocar simplemente "Si mis párpados, Lisi, labios fueran..." junto a los otros sonetos a Lisi no arroja las mismas luces sobre lo distintivo de Quevedo que si lo colocamos, por ejemplo, junto a "Si a los que me merecen me entregara...": la retórica es la misma, y también el ingenio. Otro tanto cabe decir de "Si dios eres, Amor, ¿cuál es tu cielo...?”, incluido en Canta sola a Lisi sólo porque la dama se llama Lisis (v. 13), pero que está emparentado más bien con el chistoso "Si eres campana, ¿dónde está el badajo...?”. Ateniéndonos a la consabida dualidad fondo/forma, podemos decir que lo que importa en Quevedo es mucho más la forma que el fondo ${ }^{27}$. El qué suele ser un lugar común, por ejemplo los muy traídos y llevados tópicos senequistas sobre la muerte que a todos nos acecha. Lo que importa es el cómo.

La moderna predilección por los poemas amorosos adolece de una especie de anacronismo ${ }^{28}$. Los valores implantados por los románticos alemanes, la "autenticidad", la expresión de lo "íntimo", siguen moldeando en mayor o menor medida la crítica de nuestros tiempos. ¿Qué cosa más íntima que la pasión erótica? Inevitablemente, los poemas amorosos de Quevedo, y en especial los de Canta sola a Lisi, se sienten como testimonios autobiográficos. Lisi viene a ser el tercer eslabón de una cadena: Laura, Luz, Lisi. Dámaso Alonso, al sentir que en Canta sola a Lisi se hincha la expresión "como con hervor de lágrimas", necesitaba postular una dama de carne y hueso en quien tuviera Quevedo lo que Petrarca tuvo en Laura y Herrera en la condesa de Gelves ${ }^{29}$, para así dar alguna sustancia o alguna base a su exaltada declaración (p. 554): "Quevedo es el más alto poeta de amor

${ }^{27}$ Discrepo aquí por completo de lo que dice Dámaso Alonso, Poesía española, ed. de 1952, p. 531: que en Quevedo - a diferencia de Góngora- "la ligazón significante-significado se carga o vence del lado del significado". (Lo cual no es renegar de la admiración que suscitó en mí ese ensayo cuando lo leí por primera vez hace casi medio siglo.)

${ }^{28}$ Para los poetas de las generaciones que siguieron a la de Quevedo, como Bernardino de Rebolledo y Miguel de Barrios, contaba más el Heráclito cristiano que el Canta sola a Lisi. (Sobre el quevedismo de Barrios véase mi art. "La fábula burlesca de Cristo y la Magdalena”, NRFH, 41, 1993, pp. 418-420.) El bogotano Francisco Álvarez de Velasco, que no da señales de conocer a Góngora, hizo al Quevedo "didáctico" un homenaje que se había hecho sólo a Góngora: dos sonetos y un poema medianamente largo que son centones de solos primeros versos de sonetos de Quevedo: Rhýthmica sacra, moral y laudatoria, Bogotá, 1989, pp. 308-316 y 322-325. Pero hay que reconocer que su homenaje está muy desnudo de ingenio.

${ }^{29}$ Dice (p. 549) que "lo más posible" es que los poemas a Lisi sean "una muestra de galante vasallaje a una gran dama, a quien la respetuosa pasión que los versos expresaban nunca podía ofender, sí siempre halagar”. Por otra parte, seguramente por haber leído el Amiel de Gregorio Marañón, Alonso ve en Quevedo (p. 554) uno de esos "hombres que, por demasiado hombres, no tienen mucho éxito con las mujeres". Lo malo es que esta visión no va bien con la arraigadísima y conocidísima misoginia de Quevedo. En verdad, la vida erótica de Quevedo - a diferencia de la de Lope y la de Góngora- es terra incognita. 
de la literatura española”. Más denodado que Alonso, Luis Astrana Marín había sostenido categóricamente que doña Luisa de la Cerda, dama noble, "de la casa de Medinaceli", había sido "la amada por quien suspiró en balde veintidós años Quevedo”. De esa manera podríamos exclamar: "¡Dios mío, qué amor tan intensamente vivido!”" Lo mismo sucede con los poemas de reflexión moral, como "Si a los que me merecen me entregara..." o "Si de un delito proprio es precio en Lido...", hechos para poner en boca del lector un “¡Ah, Quevedo! ¿Qué hervor de indignación ante las injusticias sociales!"31. Bastan unos momentos de recapacitación para ver que todo es Retórica, todo es arte de persuadir, cuestión de decir cosas de manera impresionante. Los sonetos amorosos dan la impresión de un enamoramiento sublime; los morales o metafísicos, la impresión de un pensamiento profundo. Pero en esa impresión consiste su enorme eficacia ("O poeta é um fingidor"). En Quevedo, gran poeta, la retórica se convierte constantemente en poesía.

El soneto "Cerrar podrá mis ojos la postrera/ sombra...", dice Dámaso Alonso (p. 562), es "probablemente el mejor de la literatura española". Yo digo otro tanto de ese soneto y de muchos otros de diferentes autores. Lo que me parece indudable es que ningún lector moderno admirará un soneto como "Si hija de mi amor mi muerte fuese...", tan artificioso, al grado de ponerlo por encima de "Cerrar podrá mis ojos...”. Y, sin embargo, bien puede ser que para Quevedo (y para sus admiradores coetáneos) el mejor haya sido el artificioso. Quevedo estuvo dándole vueltas y más vueltas al seductor concetto 'Amor constante más allá de la Muerte', y probablemente la última vuelta fue "Si hija de mi amor...". Lo que en otros ensayos había estado metido en el cuerpo del soneto, pasó aquí a ser el verso inicial, la hipótesis rarísima, la impactante imaginación de una Muerte parida por el Amor. El soneto "Si hija de mi amor..." vendría a ser como la forma definitiva de un aguafuerte que ha pasado por varios "estados" 32 . Algo parecido sucede con el soneto que ha dado

30 Astrana Marín (ed.), Verso, 1943, p. 53, nota. Se olvida Astrana de las veintitantas damas (Filis, Cloris, Floralba, Casilina, etc.) a quienes dirigió Quevedo poemas de inflamado amor, por ejemplo "Al oro de tu frente..." (a Floris) y "Pues eres sol..." (a Aminta). El verso final del soneto "Mandóme, jay Fabio!..." dice: "eterno amante soy de eterna amada" (Flora).

${ }^{31}$ De hecho, la vida pública de Quevedo, y en concreto su turbia relación con los poderosos, no deja precisamente la noble imagen de un paladín de las normas éticas.

${ }^{32}$ Esta conjetura tropieza con nuestra ignorancia de la cronología. Pero parece lógico suponer que versos como "no verán de mi amor el fin los días" (soneto "Que vos me permitáis..."), "llama que a la inmortal vida trasciende" (soneto "Diez años de mi vida..."), "y siempre en el sepulcro estaré ardiendo" (soneto "Qué perezosos pies..."), "el cuerpo frío/ se acordará de Amor en polvo y tierra" (soneto "Éstas son y serán...") y "nadar sabe mi llama la agua fría" (soneto "Cerrar podrá...") son ante- 
pretexto a mis reflexiones. La retórica del amour courtois es el cimiento de la poesía amorosa de Quevedo, sobre todo la de Canta sola a Lisi. Lo que él hace es revestirla con su propia retórica, ensayando expresiones novedosas del trovadoresco "se mira pero no se toca" - por ejemplo "también la boca a razonar aprende,/ como con llanto y sin hablar los ojos" (soneto "¿Cómo es tan largo en mí...?”)— antes de llegar a la definitiva, que es seguramente el soneto "Si mis párpados, Lisi, labios fueran...”. Aquí la idea está ya en el primer verso, del cual dependen los otros trece. ¿Cómo no leer ávidamente un soneto que comienza con esa desmesurada "hipótesis", esa arcimboldesca imaginación de un rostro con labios en vez de párpados?

Antonio Alatorre

El Colegio de México

riores a "de esotra parte de la muerte dura/ vivirán en mi sombra mis cuidados" (soneto "Si hija de mi amor..."). 